\title{
Impelementasi High Availability Mailbox Server dengan Mail Zimbra Multi Cluster Virtual Menggunakan Hypervisor Proxmox VE pada PT. LV Logistics Indonesia
}

\author{
Sudirman ${ }^{* 1}$, Mahar Faiqurahman ${ }^{2}$, Denar Regata Akbi ${ }^{3}$ \\ 1,2,3 Teknik Informatika/Universitas Muhammadiyah Malang \\ sud9429@gmail.com ${ }^{* 1}$, mahar@umm.ac.id ${ }^{2}$, dnarregata@umm.ac.id ${ }^{3}$
}

\begin{abstract}
Abstrak
Ketersediaan suatu layanan dalam suatu perusahaan merupakan hal yang harus dipenuhi agar proses bisnis yang ada dalam perusahaan dapat berjalan lancer PT. LV Logistics Indonesia saat ini masih menggunakan teknologi server mail yang selama ini masih menyesewa lisensi dari google untuk menyediakan layanan email bagi para pegawainya. Penggunaan teknologi tersebut tentu tidak dapat diandalkan apabila kita menginginkan layanan memiliki tingkat ketersediaan yang tinggi (high availability) dan untuk memotong budget pengeluaran perusahaan. Teknologi high availability mailbox server dengan mail zimbra multi cluster virtual menggunakan hypervisor proxmox ve merupakan opsi yang digunakan untuk meningkatkan layanan email di PT. LV Logistics Indonesia agar memiliki tingkat ketersediaan yang tinggi. Tingkat ketersediaan tinggi juga menjadi kelebihan yang dimiliki oleh sistem multi server mail zimbra. Jika ada server di dalam cluster yang down maka semua request akan dialihkan ke server yang masih aktif. Sehingga tidak mengganggu request yang datang ke sistem. Maka berdasarkan permasalahan diatas mendorong penulis untuk membuat dan menerapkan sistem tersebut pada PT. LV Logistics Indonesia serta membuat usulan penelitian Impelementasi High Availability Mailbox Server dengan Mail Zimbra Multi Cluster Virtual Menggunakan Hypervisor Proxmox VE pada PT. LV Logistics Indonesia dengan harapan dapat meningkatkan mutu pelayanan dan memudahkan kinerja staff di PT. LV Logistics Indonesia.
\end{abstract}

Kata Kunci: High Availability, Mail Zimbra, Hypervisor Proxmox Ve, Multi Server

Abstract

The availability of a service in a company is something that must be fulfilled so that the existing business processes in the company can run smoothly PT. LV Logistics Indonesia is still using mail server technology, which has been hiring licenses from Google to provide email services to its employees. The use of such technology is certainly not reliable if we want services to have high availability and to cut down on the company's expenditure budget. High availability technology for mailbox servers with virtual mail zimbra multi clusters using the hypervisor proxmox ve is an option used to improve email services at PT. LV Logistics Indonesia has a high level of availability. The high availability level is also an advantage possessed by the zimbra multi mail server system. If there is a server in the cluster that is down, all requests will be transferred to the active server. So, it does not interfere with requests that come to the system. So based on the above problems encourage writers to create and implement the system at PT. LV Logistics Indonesia and make a proposal for implementation of the High Availability Mailbox Server with Zimbra Multi Cluster Virtual Mail Using the Hypervisor Proxmox VE at PT. LV Logistics Indonesia in hopes of improving service quality and facilitating the performance of staff at PT. LV Logistics Indonesia.

Keywords: High Availability, Mail Zimbra, Ve Proxmox Hypervisor, Multi Server

\section{Pendahuluan}

Dengan berkembangnya teknologi saat ini, menyebabkan banyak pihak semakin mudah dalam berkomunikasi tanpa mengenal waktu dan jarak. Setiap individu dapat berkomunikasi satu dengan yang lain dengan surat, telepon, fax, bahkan yang sekarang ini sedang berkembang pesat yaitu media internet. Setiap perusahaan atau sebuah instansi pasti membutuhkan suatu alat bantu komunikasi yaitu dengan menggunakan email (electronic mail) untuk berkomunikasi. Email merupakan salah satu media komunikasi elektronik yang sering digunakan untuk 
berkomunikasi yang dapat mengirimkan informasi berupa gambar, teks dan file. Dapat dikirimkan kepada siapa saja yang terhubung dengan jaringan internet melalui email [1].

Standar yang digunakan untuk mengiriman email dalam jaringan internet atau Transmission Control Protocol / Internet Protocol (TCP/IP) adalah Simple Mail Transfer Protocol (SMTP). Mail Server berbasis SMTP dibutuhkan agar email dapat dikirim dari sumber sampai ke alamat tujuan. Ketika email sampai ke email server tujuan, user dapat membaca email yang diterima melalui beberapa cara. Salah satu caranya melalui protocol Post-Office Protocol (PO3), dimana user dapat men-download seluruh email-nya yang terdapat pada mail server untuk dibaca. Untuk memungkinkan ini maka dibutujkan mail server dengan mendukung protocol POP3 [2].

Dengan semakin populernya teknologi e-mail saat ini dikalangan masyarakat, tingkat keamanan dan kenyamanan justru semakin berkurang. Adapun beberapa penyebab berkurangnya tingkat keamanan para pengguna e-mail adalah terjangan trafik email, spam dan jumlah user yang banyak. Spam adalah e-mail yang masuk ke e-mail pengguna yang sama sekali tidak pernah diminta dan diinginkan oleh pengguna, sehingga akan membanjiri kotak masuk email pengguna, jika spam tersebut dibiarkan masuk kekotak e-mail akan membuat kapasitas penyimpanan penuh, masuknya malware dan virus yang dikirim dari spam tersebut pada akhirnya bisa membuat mail server down [2].

Untuk menghindari dan mencegah kehadiran e-mail spam dan terjangan trafik email tersebut, dibutuhkan suatu server mail yang mempunyai komponen-komponen yang lengkap sebagai pencegah spam. Mail server zimbra merupakan salah satu mail server yang didalamnya sudah tersedia Spamassassin dan Whitelist sebagai software pencegah spam. Spamassassin adalah program yang dipakai untuk menyaring spam terhadap surat yang masuk dengan cara pengecekan isi e-mail, pengecekan alamat DNS dan pengecekan checksum isi, sedangkan Whitelist adalah sebuah daftar yang diperbolehkan untuk diakses oleh komputer atau jaringan yang didalamnya terdapat beberapa alamat e-mail, ip addres dan nama domain yang dimana daftar tersebut sudah dipastikan sangat aman. Zimbra merupakan mail server open source yang bisa diinstall di linux seperti centos, Ubuntu [3].

Sistem high availability adalah suatu metode yang digunakan untuk memisahkan antara dua atau banyak link network. Dengan mempunyai banyak link maka optimalisasi kegunaan sumber daya, throughput, dan time response akan semakin baik karena mempunyai lebih dari satu link yang bisa saling membackup pada saat network down dan menjadi cepat pada saat network normal jika memerlukan kehandalan tinggi yang memerlukan $100 \%$ koneksi uptime yang berbeda dan dibuat saling membackup. Di implementasikan metode ini pada layanan mail server juga dapat meminimalisir dampak dari terjangan trafik email maupun spam email, dikarenakan bila mana server terjadi masalah / down, metode cluster dapat untuk membuat cadangan sistem agar tetap berjalan dengan normal [4].

Berdasarkan latar belakang masalah tersebut, penulis memandang penting dan mengangkat kasus diatas ke dalam tugas akhir ini dengan mengambil judul: "Impelementasi High Availability Mailbox Server dengan Mail Zimbra Multi Cluster Virtual Menggunakan Hypervisor Proxmox VE pada PT. LV Logistics Indonesia". Dan diharapkan layanan sistem multi zimbra email server yang di implementasikan pada PT. LV Logistics Indonesia berjalan secara optimal.

\section{Metode Penelitian}

Tahap kerja penelitian ini akan diuraikan pada kerangka kerja, yang mana kerangka kerja tersebut akan digunakan sebagai acuan atau langkah dalam membangun sistem "Impelementasi High Availability Mailbox Server dengan Mail Zimbra Multi Cluster Virtual Menggunakan Hypervisor Proxmox VE" yang akan di implementasikan di PT. LV Logistics Indonesia ini. Pada awalnya yang akan dilakukan yaitu melakukan analisis terhadap kebutuhan membangun sistem ini. Selanjutnya akan dilakukan dengan merancang dan menguji dari multi server mail zimbra yang diimplementasikan pada proxmox ve, serta mengetahui hasil dari pengujian penelitian ini yang nantinya akan dijadikan perbandingan.

\section{Analisa dan Perancangan Sistem \\ 3.1 Analisa Sistem}

Pada tahap ini peneliti akan membahas topologi yang diperlukan untuk membangun sistem mail server yang dikerjakan. Seperti yang sudah dijelaskan pada sebelumnya sistem ini memerlukan 1 buah server physical yang dimana 1 buah server berfungsi sebagai virtualisasi

REPOSITOR, Vol. 2, No. 5, Mei 2020: 659-666 
Proxmox yang akan digunakan untuk tempat masing-masing server node service, yang nantinya akan terinstall zimbra mail server didalam masing-masing server tersebut. Dengan konsep Multiserver, maka berbagai macam layanan didalam 1 bundle ini dipecah kedalam beberapa server, tidak lagi semua diinstall kedalam 1 buah server. Misalnya Mailbox 1 diinstall di 1 Server, LDAP di 1 Server, layanan HAProxy Load Balance diinstall 1 server terpisah, dst. Dengan membagi-bagi layanan ke beberapa server seperti ini, membuat beban kerja Zimbra menjadi terbagi. Efeknya performa Zimbra menjadi lebih ringan. Skenario pembagian layanan ke beberapa server ini bebas sesuai kebutuhan dan budget juga. Semakin banyak layanan zimbra dipecah, maka semakin besar kemampuan Zimbra. 1 Server dengan single server hanya bisa melayani 100 user, tapi 1 server yang sama dengan skema multiserver bisa melayani hingga 1000 user. Sistem ini memiliki topologi yang telah penulis rancang sendiri guna mempermudah untuk menyelesaikan proses pembahasan tugas akhir ini. Gambar 1 berikut perancangan topologi yang digunakan.

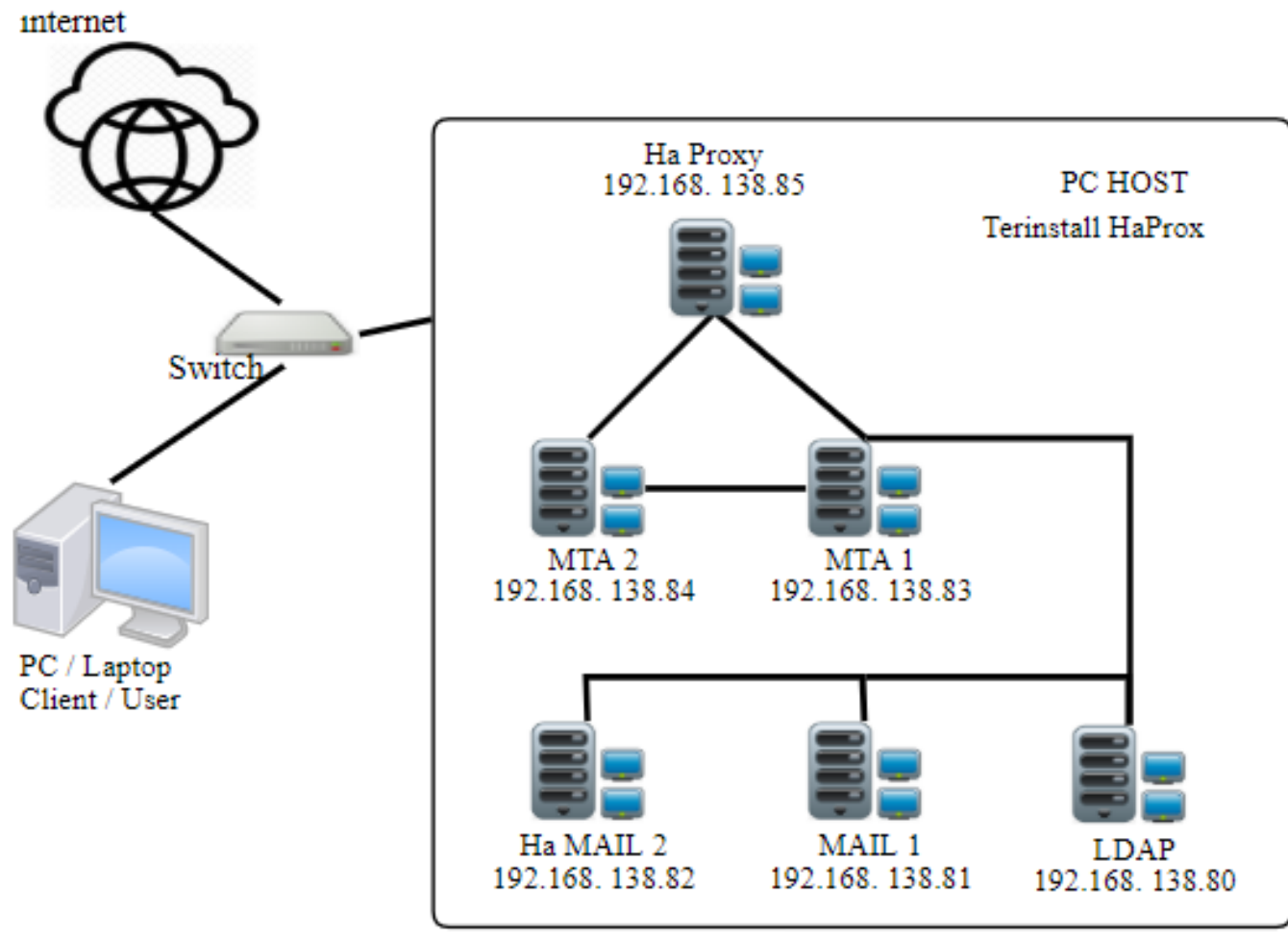

Gambar 1. Topologi Sistem

Dari Gambar 1 dapat dilihat bahwa sistem multi server tersebut dibuat dalam sebuah server yang didalamnya dibuat 6 buah server virtual yang terinstall pada sebuah 1 server physical dimana pada server virtual tersebut akan menjadi node dari cluster yang akan dibuat. Dalam pembuatan cluster tiap node memiliki perannya masing-masing yaitu, 2 server MTA, 2 server mailbox, 1 server LDAP, dan 1 server HAProxy. Service Zimbra pada penelitian tugas akhir ini membutuhkan resources yang cukup besar, apalagi jika digunakan untuk production. Supaya tiap server-server terjaga performanya dan untuk kebutuhan user atau akun dengan jumlah yang banyak, dan demi keamanan apabila server mengalami kerusakan, disini kita akan menggunakan metode multi-server, yaitu dengan memisahkan layanan - layanan pada Zimbra pada server yang berbeda sehingga setiap server dapat berjalan dengan lebih powerful.

\subsection{Analisa Kebutuhan Sistem}

Pada tahap ini akan diuraikan kebutuhan apa saja yang akan diperlukan, mulai dari perangkat keras maupun perangkat lunak yang akan digunakan pada masing-masing server.

\subsection{Kebutuhan Perangkat Keras}

Tabel 1 berikut adalah rincian dan spesifikasi perangkat keras yang akan diperlukan untuk membangun sistem ini. 
Tabel 1. Kebutuhan Perangkat Keras

\begin{tabular}{|c|c|c|}
\hline Spesifikasi & \multicolumn{2}{|l|}{ Nama Perangkat } \\
\hline Kebutuhan & Email Server 2 & Switch \\
\hline$R A M$ & $10 G b$ & - \\
\hline$C P U$ & $\begin{array}{l}\text { Intel Xeon E3-1220V2 / } 3.1 \mathrm{GHz} \\
\text { Max Turbo Speed } 3.5 \mathrm{GHz} \\
\text { Semua kebutuhan dijadikan satu karena sistem } \\
\text { dibangun secara virtual }\end{array}$ & - \\
\hline Hardisk & $500 G b$ & \\
\hline Tipe & $\begin{array}{l}\text { IBM System x3250 M4 } 2583 \text { - Xeon E3-1220V2 3.1 } \\
\text { GHz }\end{array}$ & HP 1810 \\
\hline Interface & & 48G Port \\
\hline
\end{tabular}

\subsection{Kebutuhan Perangkat Lunak}

Perangkat lunak yang diperlukan untuk membangun sistem ini seperti pada Tabel 2 yang menampilkan spesifikasi kebutuhan perangkat lunak.

Tabel 2. Spesifikasi Kebutuhan Perangkat Lunak

\begin{tabular}{ccc}
\hline \multirow{2}{*}{ Nama Perangkat } & \multicolumn{2}{c}{ Spesifikasi Kebutuhan Perangkat Lunak } \\
MTA-01 & Sistem Operasi & Software \\
\hline MTA-02 & & \\
\hline Mailbox-1 & Ubuntu 16.04 & - \\
\hline Mailbox-2 & & \\
\hline LDAP & Windows $10 \times 64$ bit & Apache Jmeter \\
\hline HAProxy & User Penguji & Wrowser \\
\hline
\end{tabular}

\subsection{Kebutuhan Domain, Hostname, IP Address, User, Password yang Digunakan}

Pada tahap implementasi sistem dibuat pada lingkup jaringan lokal yang telah dibuat. Pada Tabel 3 dibawah ini merupakan hostname, ip address, user, dan password untuk masing-masing server yang dikonfigurasi.

Tabel 3. Kebutuhan Server Mail

\begin{tabular}{cccc}
\hline HOSTNAME & IP & USER & PASSWORD \\
\hline gsldap.Ivlogist.com & 192.168 .138 .80 & gsldap & Server123 \\
gsmta1.Ivlogist.com & 192.168 .138 .83 & gsmta1 & Server123 \\
gsmta2.Ivlogist.com & 192.168 .138 .84 & gsmta2 & Server123 \\
gszimbra1.Ivlogist.com & 192.168 .138 .81 & gszimbra1 & Server123 \\
gszimbra2.Ivlogist.com & 192.168 .138 .82 & gszimbra2 & Server123 \\
gszhap.Ivlogist.com & 192.168 .138 .85 & gszhap & Server123 \\
\hline
\end{tabular}

\section{Hasil Penelitian dan Pembahasan}

Pada tahap ini akan dijelaskan hasil dan pembahasan dari penelitian tugas akhir tentang Impelementasi High Availability Mailbox Server dengan Mail Zimbra Multi Cluster Virtual Menggunakan Hypervisor Proxmox VE pada PT. LV Logistics Indonesia.

\subsection{Implementasi Sistem}

\subsubsection{Tampilan Halaman Utama User Zimbra}

Skenario Zimbra multi server dilakukan dengan cara memisahkan service-service tertentu pada server terpisah, misalnya ada pemisahan untuk fungsi LDAP server, Mailbox server, MTA server dan lain-lain. Untuk menjalankan servis email zimbra dengan skema multi server minimal dibutuhkan setidaknya 6 server.

1. Halaman Utama Login User

Pada Gambar 2 dan Gambar 3 halaman ini pengguna email zimbra bisa melakukan login. 


\section{(ब) zimbra}

rement

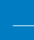

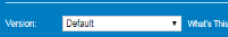

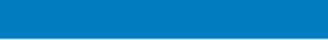

Gambar 2. Halaman Utama Login User Zimbra Mail

2. Tampilan Mail Zimbra

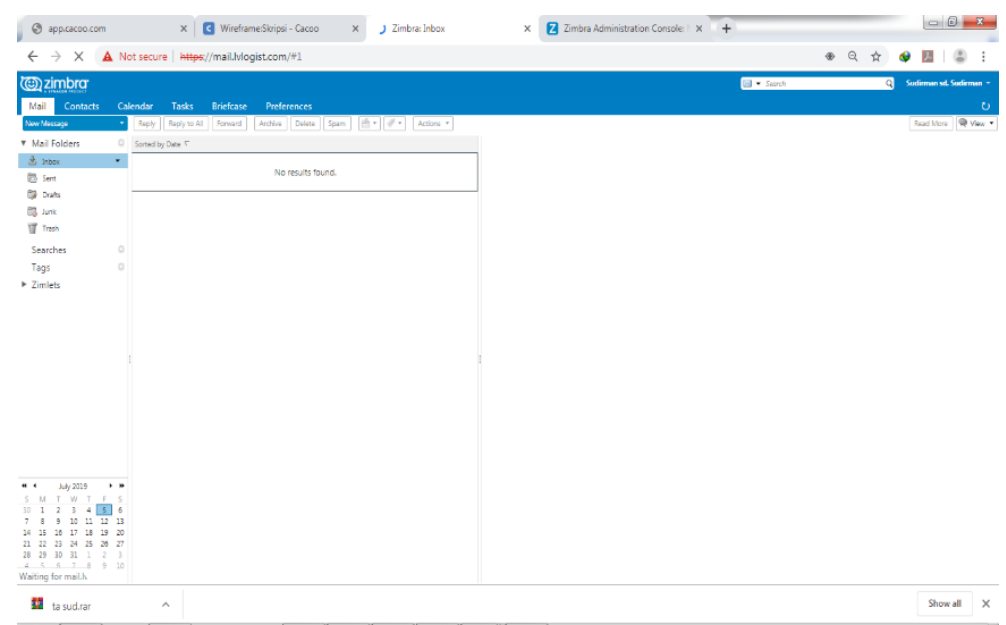

Gambar 3. Tampilan Halaman User Mail Zimbra

3. Tampilan Monitoring Server Status

Untuk bisa melihat kondisi status pada server zimbra, harus login sebagai admin dengan akses https://mail.Ivlogists.com:7071, setelah itu masuk ke menu Monitor seperti pada Gambar 4, Gambar 5, dan Gambar 6.

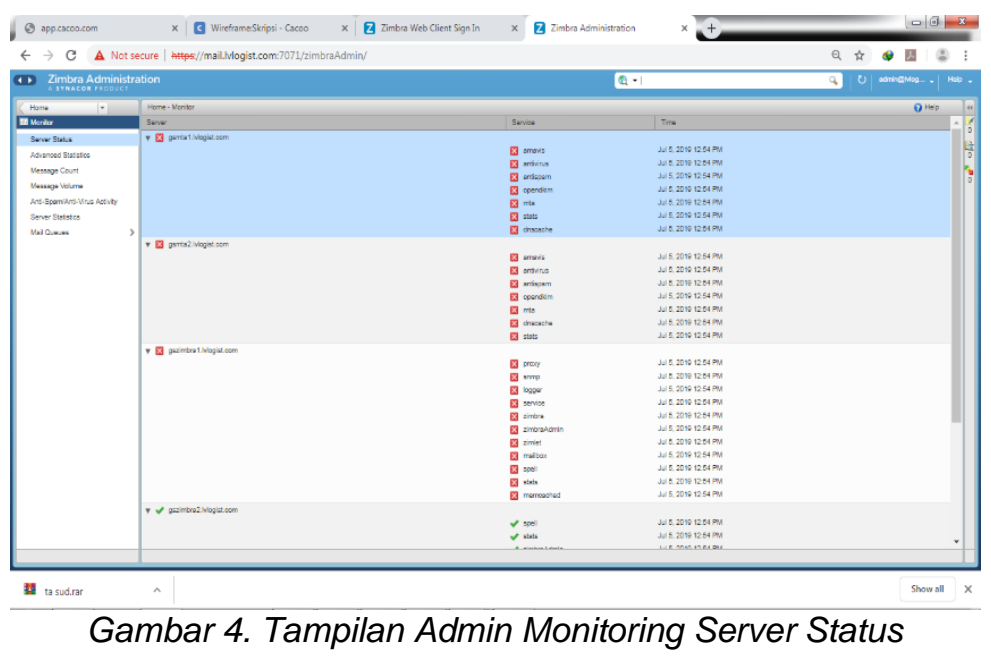


4. Tampilan Monitoring Advanced Statistic

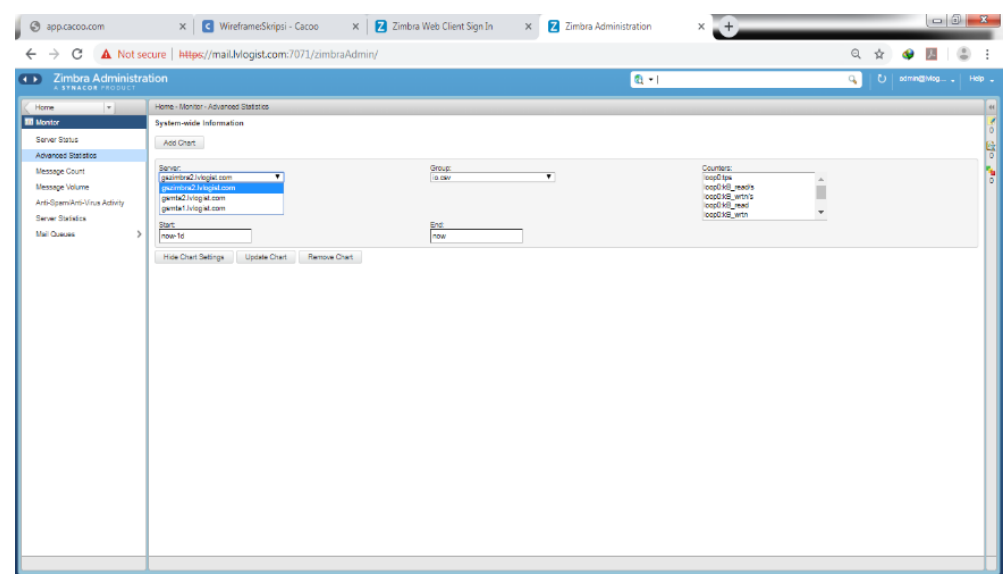

Gambar 5. Tampilan Admin Adcanced Statistic

5. Tampilan Monitoring Server Statistic

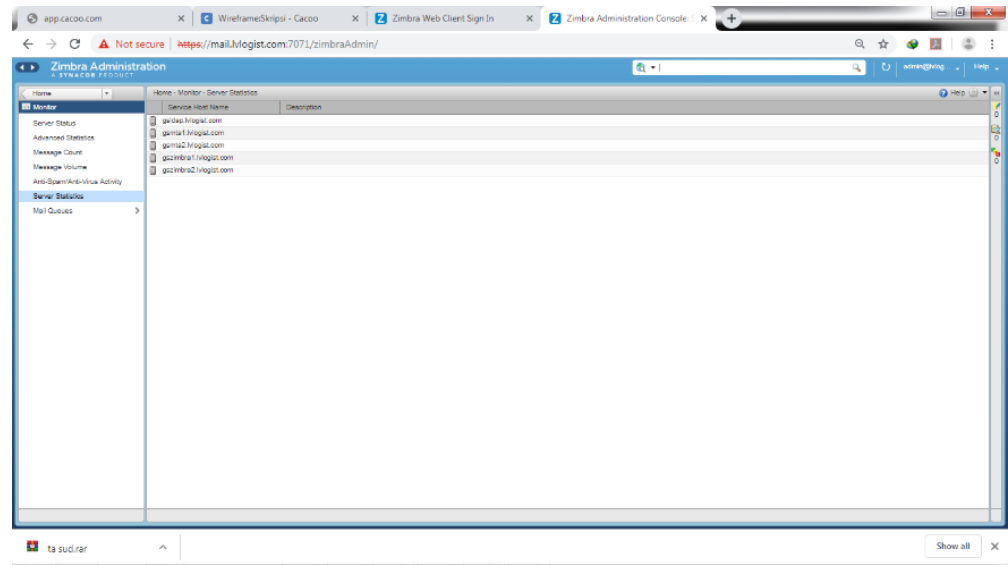

Gambar 6. Tampilan Admin Server Statistic

\section{Pengujian}

\subsection{Pengujian Aplikasi Sistem Pakar Dengan Perhitungan Akurasi}

Pengujian merupakan bagian yang tidak kalah pentingnya dalam siklus pembangunan perangkat lunak. Pengujian dilakukan untuk menjamin kualitas dan juga mengetahui kelemahan dari perangakat lunak. Tujuan dari pengujian ini adalah untuk menjamin bahwa perangkat lunak yang dibangun memiliki kualitas yang handal, yaitu mampu merepresentasikan kajian pokok dari spesifikasi, analisis, perancangan dan pengkodean dari perangkat lunak itu sendiri. Pengujian perangkat lunak ini menggunakan metode pengujian unit testing dan integration system, untuk hasil dari masing-masing tahapan pengujian tersebut dapat dilihat pada rencana pengujian dibawah.

\section{Kesimpulan}

Berdasarkan dari pembahasan yang sudah dijelaskan sebelumnya, penulis mencoba untuk menarik kesimpulan mengenai kegiatan impelementasi High Availability Mailbox Server dengan Mail Zimbra Multi Cluster Virtual Menggunakan Hypervisor Proxmox VE pada PT. LV Logistics Indonesia yaitu sebagai berikut:

1. Dalam skala trafik email yang tinggi, penerapan zimbra proxy akses webmail klien menjadi lebih cepat. Karena ada proses cache yang dilakukan oleh zimbra memcached. Juga pembagian trafik dan beban (load balancing) ke beberapa server menjadikan kinerja server tidak tersentral dalam satu server. Baik itu akses webmail (http proxy) dan mail klien pop3/IMAP (mail proxy). 
2. Spesifikasi hardware dan kualitas bandwidth sangat berpengaruh dalam proses scanning email yang masuk dan keluar. Latency delay suatu antrian email akan semakin mudah di proses jika resource server tidak di gunakan oleh servis zimbra yang lainnya.

3. Dengan penerapan zimbra di belakang NAT, menjadikan zimbra lebih secure, karena hanya port-port tertentu yang di buka dan di teruskan dari akses global internet.

4. Penerapan multi server menjadikan mail server fleksibel jika suatu saat ada penambahan server mailbox, server MTA atau server LDAP. Sehingga tidak perlu ada downtime yang cukup lama.

5. Dengan virtualisasi Proxmox Ve, menjadikan cost untuk hardware menjadi lebih hemat. Karena tidak membutuhkan space rack yang banyak, listrik dan juga suhu panas.

\section{Referensi}

[1] Aziz Zainudin, Heru Supriyono, M. M. (2012). Analisis Perbandingan Kinerja Dan Sistem Keamanan Qmail Sebagai Mail Server Stie Al-Es'Af Dengan Zimbra Mail Dan Squirrelmail. Jurnal Komunikasi Dan Informatika, 2-19.

[2] Supendar, H., \& Royman. (2016). Zimbra Collaboration Suite Dalam Membangun Web Server Berbasis Linux, 1(1), 13-26.

[3] Galih Dwiyan Prakoso, Periyadi, S.T., M.T., Henry Rossi Andrian, S.T,M.T. (2017).Implementasi Keamanan Mail Server Zimbra Menggunakan Spamassassin Dan Whitelist Pada Linux Centos 7

[4] Denar Regata Akbi, Saifuddin, Gustam Efendi. (2017) ,Redundancy Email Server Dengan Cluster Loadbalancing Untuk Mekanisme Disaster Recovery Pada Studi Kasus Pt. Jawa Pos Koran. 